\title{
Inoculum Size and Age Studies on Single and Mixed Strain Fermentation of Grape Juice
}

\author{
Sandeep Kaur ${ }^{1,2 *}$ (D) , Karamjot Kaur², Bharat Bhushan² Manveer Kaur ${ }^{2}$ and \\ Monika Hans ${ }^{3}$ \\ ${ }^{1}$ Department of Agriculture, Maharishi Markandeshwar University, Sadopur, Ambala - 134007 , India. \\ ${ }^{2}$ Department of Biotechnology, Sri Guru Granth Sahib World University, Fatehgarh Sahib - 147 407, India \\ ${ }^{3}$ Department of Food Science and Technology, Govt. P.G College for Women, Gandhi Nagar, Jammu - 180004 , \\ India.
}

\begin{abstract}
Single and mixed strain fermentation were compared to check the effect on properties of wine. Two strains of Saccharomyces cerevisiae (MTCC 11815 \& MTCC 170) were used to study the effect of inoculum age and inoculum size on fermentation of grape juice. The inoculum sizes used were $2 \%, 5 \%, 10 \%$ and $15 \%$, while inoculum age effect was studied using $24 \mathrm{~h}, 48 \mathrm{~h}$ and $60 \mathrm{~h}$ old inoculum. Fermentation efficiency of $77.2 \%$ was achieved in mixed strain culture using $15 \%$ inoculum, $17 \%$ initial sugars giving ethanol concentration of $6.70 \%(w / v)$ after $48 \mathrm{hrs}$. Fermentation efficiency of $84.65 \%$ was achieved with MTCC170 using $15 \%$ inoculum and $17 \%$ initial sugars giving ethanol concentration of $7.34 \%(w / v)$ in $48 \mathrm{hrs}$. Strain MTCC11815 produced $8.5 \%(\mathrm{w} / \mathrm{v})$ ethanol from $17 \%$ initial sugars giving $98 \%$ efficiency using 2 and $5 \%$ inoculum. Concentration of phenolics increased with inoculum concentration while nitrogen and phosphates did not show any regular trend. The nitrogen and phosphate concentration was affected by type of strain rather than other factors.
\end{abstract}

Keywords: Mixed strain fermentation, phenolics, inoculum age, inoculum size, Saccharomyces cerevisiae

\footnotetext{
*Correspondence: ksandeep579@gmail.com; +91 9872193709
}

(Received: June 13, 2020; accepted: August 20, 2020)

Citation: Kaur S, Kaur K, Bhushan B, Kaur M, Hans M. Inoculum Size and Age Studies on Single and Mixed Strain Fermentation of Grape Juice. J Pure Appl Microbiol. 2020;14(3):2137-2145. doi: 10.22207/JPAM.14.3.54

(C) The Author(s) 2020. Open Access. This article is distributed under the terms of the Creative Commons Attribution 4.0 International License which permits unrestricted use, sharing, distribution, and reproduction in any medium, provided you give appropriate credit to the original author(s) and the source, provide a link to the Creative Commons license, and indicate if changes were made. 


\section{INTRODUCTION}

Wine making is one of the oldest techniques known to the civilization and even today it is one of the most commercially prosperous biotechnological processes (Moreno-Arribas and Polo, 2005). Microorganisms have a prominent role in determining the chemical composition of wine as they metabolize fruit sugars and other components into ethanol, carbon dioxide and hundreds of secondary end-products that collectively contribute to the wine character (Lambrechts and Pretorius; 2000).

The commercial alcoholic fermentation is normally batch type and requires preparation of fresh inoculum for every new batch as a result of which an initial lag phase is observed during fermentation. This lag may be reduced by recycling yeast from previous fermentation lots (Puri et al., 2012). Recycling of yeast inoculum has been considered as an important parameter in lowering wine production costs with improved fermentation performance (Krasucki, 2011). Inoculum size and age have always been critical in deciding fermentation yields. Low inoculum concentration adversely effects the mechanism of fermentation process, thus causing much lower yield and rate of product formation, while high cell concentration causes increased activities of organisms which end up utilizing the fermentation end results for their growth and in the process limit the yield and rate of formation of fermentation products as well (Lee et al, 2008).

Length of lag phase is affected by size of inoculum and its physiological conditions and its always preferred to transfer inoculum in log phase of growth, when the cells are still metabolically active (Lincoln, 1960). Age of inoculum is considered important in case of sporulating bacteria, as sporulation occurs at the end of log phase (Lincoln, 1960; Ray et al., 2007).

Phenolic compounds are one of the major quality factors in wine grapes and in the resulting wines. In addition, phenolic compounds have a direct effect on some important organoleptic characteristics of wines, such as color, flavor, bitterness, and astringency (Garrido \& Borges, 2011). These compounds are present in grape skin, flesh and seed and are known to posses natural antioxidant and health protective properties.

According to Styburski et al. (2018) phosphorous content of the wort has strong influence on the quality, colour and taste of the beer. Nitrogenous compounds are known to effect fermentation process, final chemical composition of the wine and its aroma (tools.thermofischer. com).

Mixed strain fermentation have been explored since some time as to know about the synergistic effect of the varied cultures on the volatile and sensory properties of the wine.It has been confirmed that the volatile profiles created by mixed fermentation cannot be created by individual fermentations (Howell et al, 2006). But the interest is mainly on studying the effect of Saccharomyces and non-Saccharomyces species combination, in which many a times Saccharomyces is known to have antagonistic effect on the non-Saccharomyces species as toxic compounds produced by Saccharomyces starter culture are known to kill the non-Saccharomyces species added late in fermenting wort (PerezNevado et al., 2006).

During our literature search we did not come across mixed strain fermentation involving Saccharomyces species only. The current study was under taken with objective of observing effect of mixed Saccharomyces species fermentation and inoculum age and size on pure and mixed strain fermentation.

\section{MATERIALS AND METHODS Chemicals}

All the chemicals and reagents used in the present study were of analytical grade and procured from Bio-Red, Himedia.

\section{Procurement and maintainance of micro- organism strains}

Yeast strain of Saccharomyces cerevisiae MTCC 11815 procured from P.A.U, Ludhiana and MTCC 170 procured from IMTECH, Chandigarh were used for the present investigations. and were maintained on Glucose yeast extract (GYE) agar slants.

\section{Procurement of Raw Material}

The fully ripened grapes was collected in the month of February from Khanna, Punjab and sorted by shape and ripeness. Then collected grapes was washed with water and mixed with a blender. The juice along with skins was stored at $4^{\circ} \mathrm{C}$ for further use. The fruit juice thus obtained 
was analyzed for $\mathrm{pH}$, total soluble solids $\left({ }^{\circ} \mathrm{B}\right)$, total sugars and reducing sugars after filtration through double muslin cloth.

\section{Preparation of Must}

The must was pasteurized by heating at $60^{\circ} \mathrm{C}$ for $30 \mathrm{~min}$ to inactivate wild microorganisms. The initial total soluble solids (TSS) of the wort was adjusted to $17^{\circ} \mathrm{B}$. Diammonium hydrogen phosphate $(0.1 \%, \mathrm{w} / \mathrm{v})$ as nitrogen source for yeast was added. To inhibit the growth of undesirable microbes, potassium metabisulphite (100 ppm) was also added.

\section{Production of wine}

The must was inoculated with $10 \%$ $(\mathrm{v} / \mathrm{v})$ of $24 \mathrm{~h}$ old culture (unless and otherwise specified) of Saccharomyces cerevisiae MTCC 170 and 11815 . Fermentation was carried out at $30^{\circ} \mathrm{C}$ till the readings were constant under stationary conditions.

\section{Optimization of inoculum size}

To investigate the effect of inoculum size on fermentation of wine, the must was inoculated with $2 \%, 5 \%, 10 \%$ and $15 \%$ inoculum containing 1 $\times 10^{5}$ cells $/ \mathrm{ml}$.

\section{To study the effect of age of inoculum}

To investigate the effect of age of inoculum on wine, the fermentation was carried out with $24 \mathrm{hr}, 48 \mathrm{hr}$ and $60 \mathrm{hr}$ old inoculum.

\section{Conditions for fermentation}

- Sugar conc: as per brix of juice

- $\mathrm{pH}: 5.5$

- Temperature: $30^{\circ} \mathrm{C}$

All experiments were performed in triplicates and readings given are the mean of triplicate readings.

\section{Analytical Techniques}

Total soluble solids (TSS) in wine were determined by using Erma hand refractometer of $0-32^{\circ} \mathrm{Brix}$. . The $\mathrm{pH}$ of the samples was determined by using digital $\mathrm{pH}$ meter. Reducing sugars of fruit juice/wine were estimated by 3, 5-dinitrosalicylic acid (DNSA) method (Miller et al; 1959) and ethanol content was estimated after distillation by method described by Caputi et al; (1968). Folin \& Ciocalteu's phenol assay was used for determination of phenolic content in grape wine. Nitrogenous compounds analysis was done using Formol titration technique. Ascorbic acid method was used for determination of phosphate content in wine.
Cell count was determined by hemocytometer. Statistical analysis was performed by using the software origin 6.0

\section{Calculations}

The ethanol concentration was determined by the ethanol standard curve.

The other calculations were made as follows:-

1. Sugar utilized = Initial sugar conc. (\%) residual sugar conc. (\%).

2. Ethanol fermentation efficiency $(\%)=$ actual ethanol produced $\%(w / v) \times 100 /$ theoretical ethanol produced

3. Theoretical ethanol production $\%(w / v)=$ sugar utilized $\times 0.51$

\section{RESULTS AND DISCUSSION}

Effect of inoculum size

Four inoculum sizes viz. $2 \%, 5 \%, 10 \%$ and $15 \%$ were used to study the effect of inoculum size on ethanol content and other components of grape wine.

From $2 \%$ inoculum $8.5,3.71$ and $4.34 \%$ $(\mathrm{w} / \mathrm{v})$ ethanol concentration was obtained from S.cerevisiae MTCC 11815 (Table 1), S.cerevisiae MTCC 170 (Table 2) and mixed strain (Table 3) respectively. While the same ethanol concentration was achieved with $5 \%$ inoculum using S.cerevisiae MTCC 11815 strain, 4.35 and $5.42 \%(\mathrm{w} / \mathrm{v})$ and 8.07 , 6.53 and $5.72 \%(w / v)$ ethanol concentrations were obtained with $5 \%$ and $10 \%$ inoculum respectively. Use of $15 \%$ inoculum gave final ethanol concentration of $7.01,7.34$ and $6.7 \%(\mathrm{w} / \mathrm{v})$ for S.cerevisiae MTCC 11815, S.cerevisiae MTCC 170 and mixed strain fermentation respectively. It was observed that fermentation efficiency was maximum (98\%) for S.cerevisiae MTCC 11815 with 2 and $5 \%$ inoculum size and it decreased to $93 \%$ and $80 \%$ as the inoculum size increased to 10 and $15 \%$ respectively (Table 1 ). For S.cerevisiae MTCC 170 , fermentation efficiency increased from $42.8 \%$ to $84.6 \%$ (Table 2) as the inoculum size increased from 2 to $15 \%$. Similarly, fermentation efficiency increased from 50 to $77.2 \%$ for 2 and $15 \%$ inoculum size respectively in mixed strain fermentation. Although it still remained less than single strain fermentation. Duhan et al. (2013) observed that fermentation efficiency of S.cerevisiae MTCC 170 increased as inoculum size increased from 5 to $15 \%$ but maximum efficiency (91.39\%) was achieved with $10 \%$ inoculum. According to Breisha (2010) 


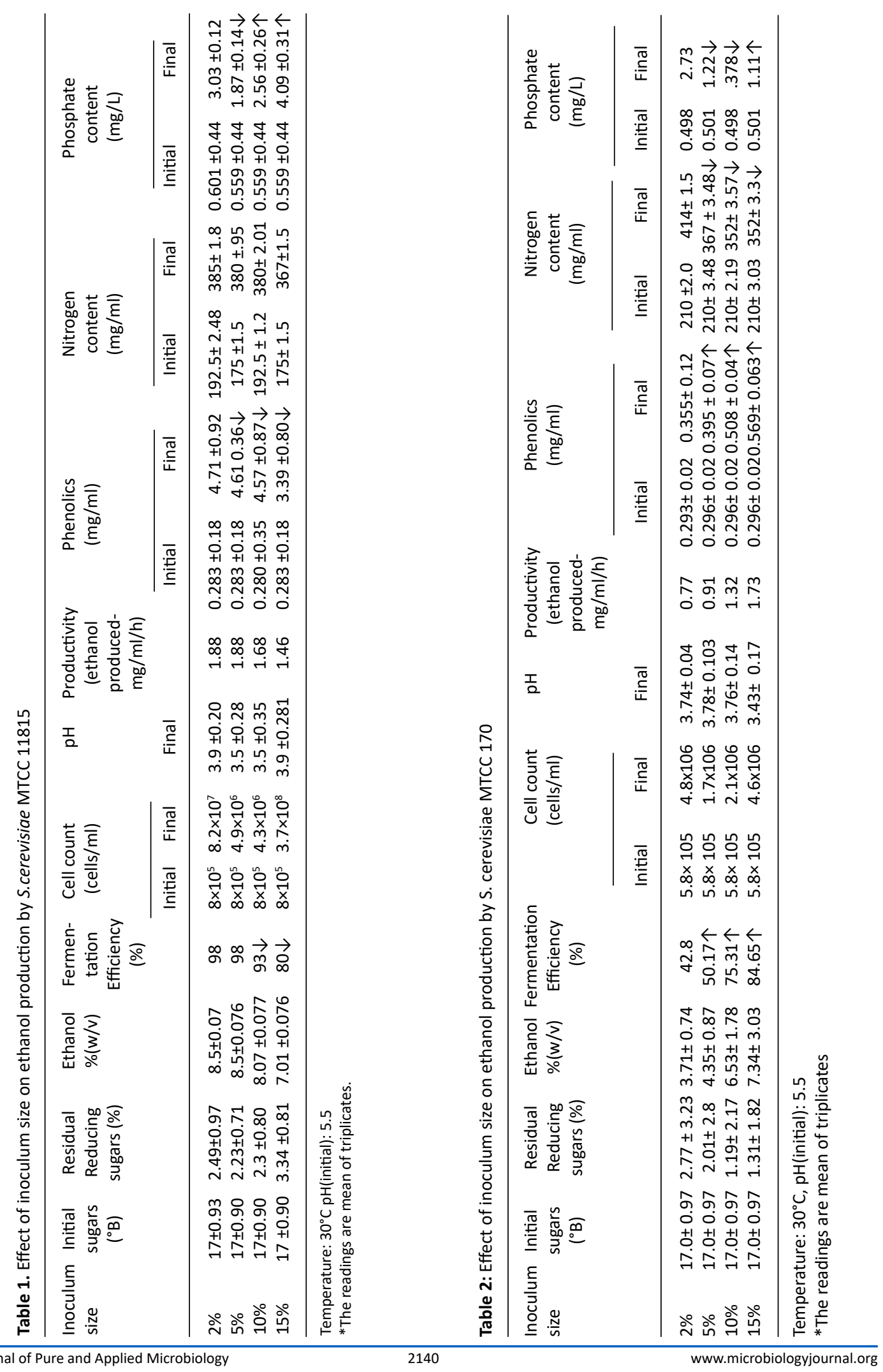



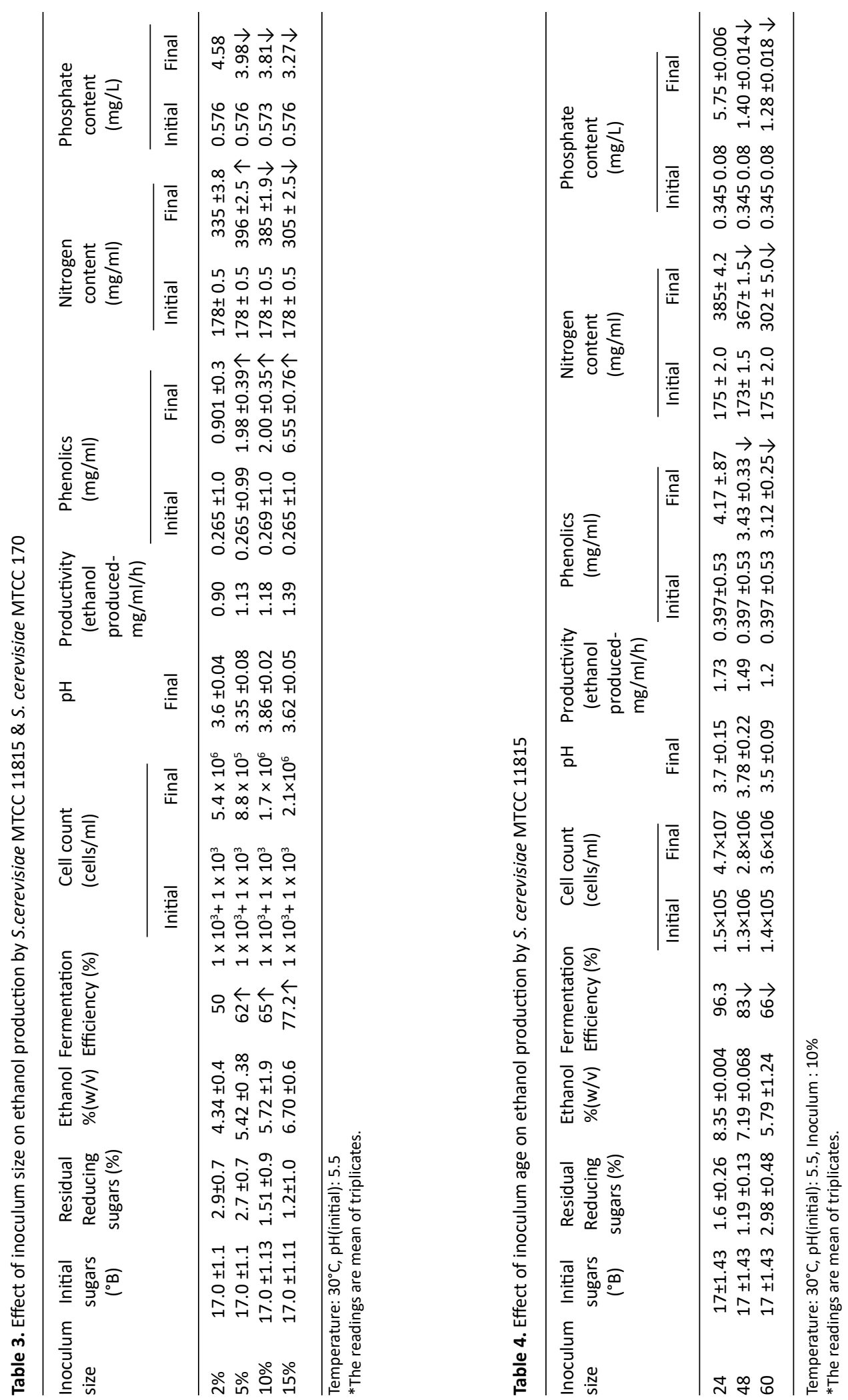


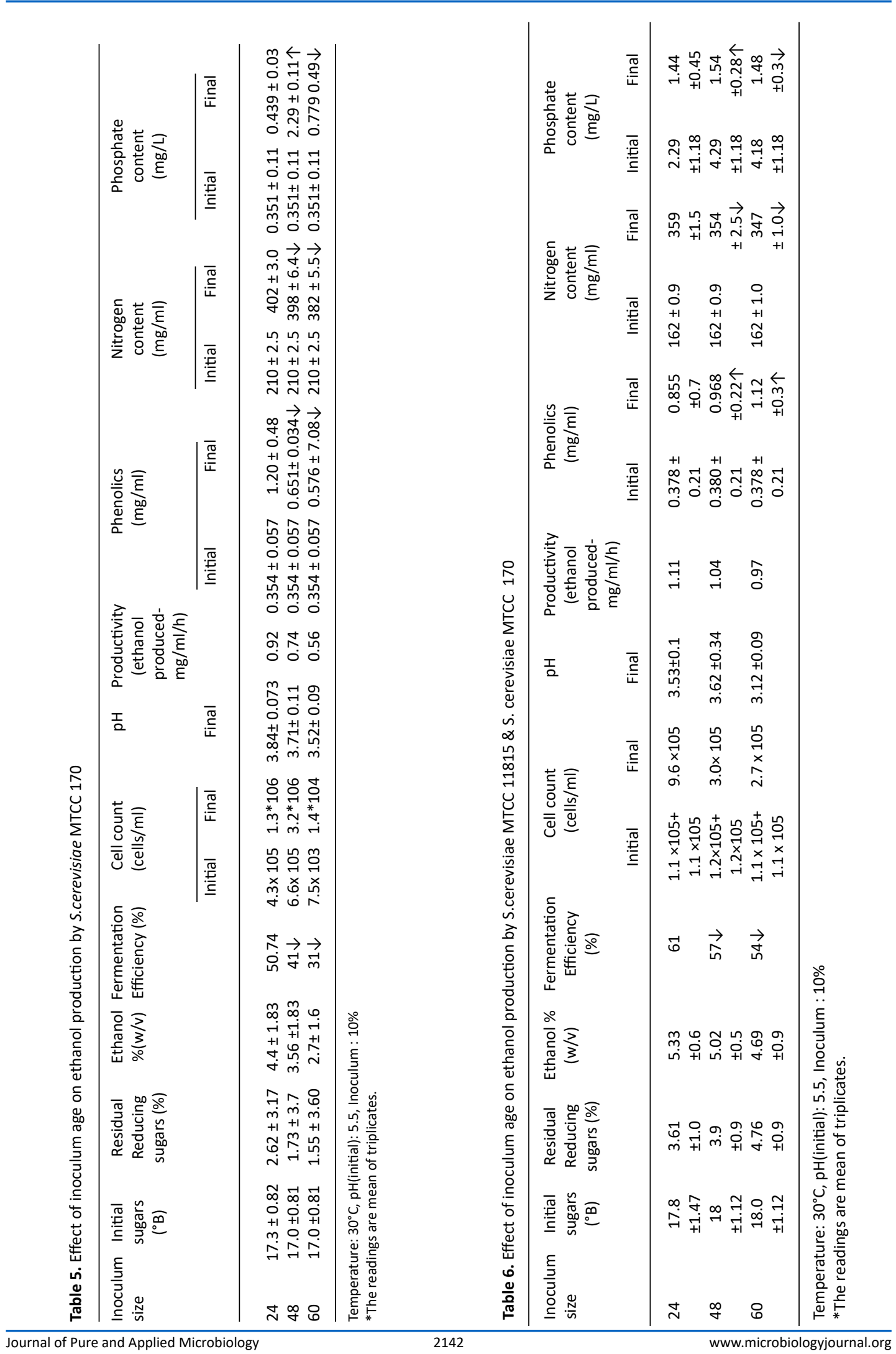


increase in inoculum concentration from 3 to $6 \%$ reduced the fermentation time by $6 \%$. Kaur et al. (2007) obtained 7\% ethanol concentration from 15\% initial sugars (substrate- malt) using 6\% inoculum of S.cerevisiae MTCC 11815. Kaur et al (2019) obtained $8.84 \%$ ethanol (substrate rice) using 10\% inoculum S.cerevisiae MTCC 11815 giving fermentation efficiency of $86.6 \%$.

In fermentation with S.cerevisiae MTCC 11815 (Table 1), a drop (4.71 to $3.39 \mathrm{mg} / \mathrm{ml}$ ) in the concentration of phenolics was observed while the phosphate content increased (3.03 to $4.09 \mathrm{mg} / \mathrm{l}$ ) as the inoculum size increased from 2 to $15 \%$. No constant trend was observed in nitrogen content. For S.cerevisiae MTCC 170 (Table 2), the phenolics concentration increased from 0.355 to 0.569 $\mathrm{mg} / \mathrm{ml}$ with incoculum size. Nitrogen content decreased from $414 \mathrm{mg} / \mathrm{ml}$ to $352 \mathrm{mg} / \mathrm{ml}$ with increase in inoculum concentration and the phosphate content decreased from 2.73 to 1.11 $\mathrm{mg} / \mathrm{l}$.

Phenolics content continued to increase with increase in inoculum size in mixed strain fermentation (Table 3) also as it increased from $0.901 \mathrm{mg} / \mathrm{ml}$ ( $2 \%$ inoculum) to $6.55 \mathrm{mg} / \mathrm{ml}$ (15\% inoculum). Both nitrogen (335 to $305 \mathrm{mg} / \mathrm{ml}$ ) and phosphate ( 4.58 to $3.27 \mathrm{mg} / \mathrm{l}$ ) content decreased with increase in inoculum concentration with mixed strain fermentation.

\section{Effect of inoculum age}

To study the effect of inoculum age on alcohol concentration three age parameters viz. 24 $h, 48 \mathrm{~h}$ and $60 \mathrm{~h}$ were chosen and $10 \%$ inoculum size was used.

As the age of inoculum increased from 24 to $60 \mathrm{~h}$, the concentration of ethanol produced decreased and so did the concentration of different chemicals produced when S.cerevisiae MTCC 11815 (Table 4) was used for fermentation. From initial sugar content of $17^{\circ} \mathrm{Brix}$, ehanol concentration of $8.35 \%(\mathrm{w} / \mathrm{v})$ was obtained with 96.3\% fermentation efficiency using $24 \mathrm{~h}$ old inoculum, which decreased to $7.19 \%(\mathrm{w} / \mathrm{v})$ ethanol concentration giving $83 \%$ fermentation efficiency with $48 \mathrm{~h}$ old inoculum and $5.79 \%(\mathrm{w} / \mathrm{v})$ ethanol was produced with $66 \%$ fermentation efficiency with $60 \mathrm{~h}$ old inoculum.

The concentration of phenolics and nitrogen and phosphates decreased from 4.17 to $3.12 \mathrm{mg} / \mathrm{ml}, 385$ to $302 \mathrm{mg} / \mathrm{ml}$ and 5.75 to 1.28 $\mathrm{mg} / \mathrm{I}$ respectively as the age of inoculum increased from $24 \mathrm{~h}$ to $60 \mathrm{~h}$.

Similar results were obtained when S.cerevisiae MTCC 170 (Table 5) was used as fermenting strain. Ethanol concentration decreased from $4.4 \%(\mathrm{w} / \mathrm{v})$ to $2.7 \%(\mathrm{w} / \mathrm{v})$ as the age of inoculum increased from 24 to $60 \mathrm{~h}$. The corresponding fermentation efficiency for 24, 48 and $60 \mathrm{~h}$ old inoculum were 50.74, 41 and 31\% respectively. The phenolics content was $1.2 \mathrm{mg} /$ $\mathrm{ml}$ after using $24 \mathrm{~h}$ inoculum which decreased to $0.576 \mathrm{mg} / \mathrm{ml}$ with $60 \mathrm{~h}$ old inoculum. Similarly nitrogen content decreased from $402 \mathrm{mg} / \mathrm{ml}$ to $382 \mathrm{mg} / \mathrm{ml}$. Phosphate concentration increased as age of inoculum increased from 24 to $48 \mathrm{~h}$ but decreased with further increase in inoculum age.

In mixed strain fermentation (Table 6), final ethanol concentration of $5.33 \%(w / v)$ giving $61 \%$ fermentation efficiency was obtained using 24 h old inoculum, which decreased to $4.69 \%$ (w/v) with $60 \mathrm{~h}$ old inoculum. The ethanol concentration obtained with mixed strain was better than results obtained from S.cerevisiae MTCC 170 single strain fermentation. Against the trend of decreasing compound concentration with increase in inoculum age, the phenolics concentration increased from 0.855 to $1.12 \mathrm{mg} / \mathrm{ml}$ with increase in inoculum age from 24 to $60 \mathrm{~h}$ respectively. The nitrogen content continued to decrease with increase in inoculum age, as it fell from 359 to 347 $\mathrm{mg} / \mathrm{ml}$ for 24 and $60 \mathrm{~h}$ inoculum respectively. The concentration of phosphates increased with use of $48 \mathrm{~h}$ old inoculum but decreased with further increase in age. It was also observed that amount of reducing sugars were left unused during mixed strain fermentation as residual sugar content was comparatively higher the amount left in single strain fermentations. Nogueira et al. (2008) reported that nitrogen content in wine varied with cider variety and mainly depended upon the initial concentration of nitrogen present in the wort. Nogueira et al. (2008) also observed that concentration of different polyphenols varied with apple variety and increase or decrease in concentration of polyphenols depended upon factors like method of juice extraction, oxidation during extraction and interaction of the yeast cell wall with different varieties of polyphenols during fermentation. Zou et al (2017) observed that concentration of phenolic compounds increased 
with alcoholic fermentation and decreased with acetic acid fermentation. Samoticha et al. (2019) reported decrease in concentration of phenolic compounds with increase in ethanol content.

Yeast inoculum size has a significant effect for ethanol production (Turhan et al., 2010). Gibbons and Weastby (1986) reported that a 5\% inoculum resulted in rapid yeast and ethanol production and higher inoculum showed no advantages. Tahira et al. (2010) using a different inoculum at $1-5 \%$ observed that the amount of ethanol produced gradually increased with the increase in the inoculum. Inoculum size for microbial growth which prevent growth vary with inoculum size.

The age of inoculum certainly had a detrimental effect on the final ethanol yield as ethanol produced decreased with increase in inoculum age. High inoculum size can also be the reason for decrease in fermentation efficiency as more substrate is utilized for maintaining high population of fermenting microorganism. Pramanik et al, (2003) observed that the maximum (9.1\%) ethanol was produced by using 15 days old inoculum. Further increase and decrease in inoculum age resulted in decreased ethanol yield. At particular cell density, growth phase of yeast cells is slow and life cycle deviates from the growth path. Manikandan et al (2010) found that $24 \mathrm{~h}$ old slant of S.cereviasae gave higher yield of ethanol compared to $48 \mathrm{~h}$ old slant.

\section{ACKNOWLEDGMENTS}

The authors want to thank Dr. Manwinder Kaur, Assistant Professor, GSSGGS Khalsa College, Patiala, India for her help in carrying statistical analysis of the work.

\section{CONFLICT OF INTEREST}

The authors declare that there is no conflict of interest.

\section{AUTHOR'S CONTRIBUTION}

The findings presented in this paper are Master's Research work of KK, BB and MK under guidance of Dr. SK. KK worked with Sachharomyces cerevisiae MTCC 1185 strain and MK worked with S. cerevisiae MTCC 170 strain. BB worked on mixed strain fermentation. The findings of all three have been combined in this research article. Dr. $\mathrm{MH}$ was minor guide to the scholars and helped in experiment performance.

The research work was performed at Sri Guru Granth Sahib World University, Fatehgarh Sahib, Punjab, India. Corresponding author and Major Guide of the scholars is currently employed at Maharishi Markandeshwar University, Sadopur, Ambala, India. Two of the scholars KK and BB are employed with Paraxel, Mohali,India while MK is preparing for competitive exams. Dr. $\mathrm{MH}$ is presently working at Jammu, India.

\section{FUNDING}

None.

\section{ETHICS STATEMENT}

Not applicable.

\section{DATA AVAILABILITY}

This report is compilation of thesis of three students and results submitted are summary of results obtained. The detailed data can be provided if required.

\section{REFERENCES}

1. Breisha GZ. Production of $16 \%$ ethanol from $35 \%$ sucrose. Biomass Bioeng. 2010;34(8):1243-1249. doi: 10.1016/j.biombioe.2010.03.017

2. Caputi AJR, Masao U, Brown J. Spectrohotometric determination of ethanol in wine. Amer J Enol Viticul. 1968;19:160-165

3. Duhan JS, Kumar A, Tanwar SK. Bioethanol production from starchy part of tuberous plant (potato) using Saccharomyces cerevisiae MTCC-170. African J Microbiol Res. 2013;7(46):5253-5260. doi: 10.5897/ AJMR2013.6122

4. Garrido J, Borges F. Wine and Grape Polyphenols. A Chemical Perspective. Food Res Int. 2011;44(10):33143148.

5. Gibbons WR, Westby CA. Effect of inoculum size in solid-phase fermentation of fodder beets for fuel ethanol production. Appl Environ Microbiol. 1986;52(4):960-962. doi: 10.1128/AEM.52.4.960962.1986

6. Kaur S, Kocher GS, Phutela RP and Soni G. Production of malt vinegar and its antioxidant potential. $J$ Res $P A U$. 2007;44(4):326-29.

7. Kaur S, Oberoi HS, Phutela RP. Isolation and Characterization of a Non- Saccharomyces Yeast with Improved Functional Characteristics for Ethanol Production. Microbiol Res J Int. 2018;26(4):1-9. doi: 10.9734/mrii/2018/v26i430073

8. Krasucki P. Yeast management provides stable performance. http://www.ethanolproducer.com/ articles/7786/yeast-management-provides-stablefermentation-performance. 2011. Accessed March,17, 
2020.

9. Lambrechts MG, Pretorius IS. Yeast and its importance to wine aroma - A review. South African J Enol \& Viticulture. 2000;21:97-129. doi: 10.21548/21-1-3560

10. Lee SY, Park JH, Jang SH, Nielsen LK, Jung KS. Fermentative butanol production by Clostridia. Biotechnol Bioeng. 2008;101(2):209-228. doi: 10.1002/ bit.22003

11. Lincoln RE. Control of stock culture preservation and inoculum build-up in bacterial fermentation, $J$ Biochem \& Microbiol Tech \& Engg. 1960;2(4):481-500. doi: 10.1002/jbmte.390020410

12. Manikandan K, Viruthagiri T. Kinetic and optimization studies on ethanol production from corn flour. Int J Chemical \& Biolog Engg. 2010;2(3):65-69.

13. Miller GL. Use of 3, 5-Dinitrosalicylic acid reagent for determination of reducing sugars. Anal Chem. 1959;31(3):426-428. doi: 10.1021/ac60147a030

14. Moreno-Arribas MV, Polo MC. Winemaking biochemistry and microbiology: Current Knowledge and Future Trends. Crit Rev Food Sci Nutr. 2005;45(4):265286. doi: $10.1080 / 10408690490478118$

15. Nogueira A, Sylvain $G$, Nathalie $M$, Jean $M L$, Jean-Francoise D, Gilvan W. Effect of Alcoholic Fermentation in the Content of Phenolic Compounds in Cider Processing. Brazilian Archives of Biol \& Technol. 2008;51(5):1025-1032. doi: 10.1590/S151689132008000500020

16. Perez-Nevado F, Albergaria H, Hogg T, Girio F. Cellular death of two non-Saccharomyces wine-related yeasts during mixed fermentations with Saccharomyces cerevisiae. Int J Food Microbiol. 2006;108(3):336-45. doi: 10.1016/j.ijfoodmicro.2005.12.012

17. Pramanik K. Parametric Studies on Batch Alcohol Fermentation Using Saccharomyces Yeast Extracted from Toddy. J Chin Inst Chem Engrs. 2003;34(4):487492.
18. Puri R, Kocher GS, Phutela RP. Optimization of yeast inoculum for ethanol production for sugarcane vinegar. J Res Punjab Agric Univ. 2012;49(1\&2):45-47.

19. Ray AK, Bairagi A, Sarkar Ghosh K, Sen SK. Optimization of fermentation conditions for cellulase production by Bacillus subtilis $\mathrm{CY} 5$ and Bacillus circulans TP 3 isolated from fish gut. Acta Ichthyol Piscat. 2007;37(1):47-53. doi: 10.3750/AIP2007.37.1.07

20. Samoticha J, Wojdylo A, Joanna C, Chmielewska J, Nofer J. Effect of Different Yeast Strains and Temperature of Fermentation on Basic Enological Parameters, Polyphenols and Volatile Compounds of Aurore White Wine. Foods. 2019;8(12):599-616. doi: 10.3390/foods8120599

21. Styburski D, Katarzyna J, Baranowska-Bosiacka I, et al. Beer as a potential source of macroelements in a diet: the analysis of calcium, chlorine, potassium, and phosphorus content in a popular low-alcoholic drink. Eur Food Res \& Technol. 2018;244:1853-1860. doi: 10.1007/s00217-018-3098-0

22. Tahira A, Aftab M, Farasat T. Effect of cultural conditions on ethanol production by locally isolated Saccharomyces cerevisiae BIO-07. App Pharma. 2010;3(2):27-78. doi: 10.21065/19204159.2.72

23. Tuhran I, Biakla KL, Demirci A, Karhan M. Ethanol production from carrot extract by using Sachharomyces cerevisiae. Bioresouce Technol. 2010;101(14):52905296. doi: 10.1016/j.biortech.2010.01.146

24. Wine analysis: from 'Grape to Glass'. An analytical testing digest of the wine manufacturing process. http://tools.thermofisher.com/content/sfs/brochures/ XX-72102-Wine-Analysis-XX72102-EN.pdf. Accessed on April, 18, 2020

25. Zou Bo, Jijun Wu, Yuanshan Yu, Gengsheng Xiao Yujuan $\mathrm{Xu}$. Evolution of the antioxidant capacity and phenolic contents of persimmon during fermentation. Food Sci Biotechnol. 2017;26(3):563-571. doi: 10.1007/s10068017-0099-x 